\title{
RESPIRATORY DISTRESS SYNDROME OF THE NEWBORN-PRINCIPLES IN TREATMENT
}

\author{
BY \\ M. A. WARLEY and DOUGLAS GAIRDNER \\ From the Department of Medicine, University of Cambridge and the Cambridge Maternity Hospital
}

(RECEIVED FOR PUBLICATION APRIL 30, 1962)

The cause of the respiratory distress syndrome (RDS) is unknown, hence management of the condition must at present rest on (i) recognition of the physiological disturbances present in the individual case; and (ii) correction of these disturbances, so far as this may be possible, in order that the baby can be given optimal conditions for survival during what is, in a proportion of cases at least, a self-limited illness.

The function of the lungs being to take in $\mathrm{O}_{2}$ and to excrete $\mathrm{CO}_{2}$, the course of the respiratory failure seen in infants with RDS can best be followed by observing the changes in the amounts of these gases in arterial blood. A secondary function of the lungs is in the maintenance of normal $p \mathrm{H}$ by regulating the amount of carbonic acid in the body. In studying respiratory function in individual cases of RDS we have, therefore, largely depended on serial measurements of four variables-the $\mathrm{O}_{2}$ saturation, $\mathrm{PCO}_{2}, p \mathrm{H}$ and bicarbonate of arterial blood.

\section{Material and Methods}

The infants studied were those who, because of the presence of respiratory symptoms during the first few hours of life, were considered likely to develop RDS. These symptoms were rapid or laboured breathing, apnoeic spells, indrawing of ribs or sternum, or expiratory moan. A majority of the infants were premature, but some of the most severe cases of RDS were born at term.

The infants were nursed in an incubator, the temperature of which was adjusted to maintain the baby's rectal temperature near to $37^{\circ} \mathrm{C}$. As it was desired to observe the effect of widely different concentrations of inspired $\mathrm{O}_{2}$, and at times to use high concentrations, it was sometimes convenient to enclose the baby's head in a small 'perspex' hood which easily fitted within the incubator (see Fig. 6). High $\mathrm{O}_{2}$ levels could thereby be maintained with low flow rates of $\mathrm{O}_{2}$ to the hood. This $\mathrm{O}_{2}$ supply could be independently warmed and humidified. Ambient $\mathrm{O}_{2}$ levels were measured with a Beckmann D2 analyser.

Arterial samples from an iliac artery were obtained by means of a plastic catheter (O.D. $2 \mathrm{~mm}$.) inserted into an umbilical artery. With experience it was found possible to introduce the catheter in almost every infant, including those of less than $1 \mathrm{~kg}$. After taking a blood sample the catheter was filled with heparin saline (50 units $/ \mathrm{ml}$.) which prevented clotting for a period of up to eight hours. The end of the catheter was then closed, and the cord stump and surrounding skin powdered with chlorhexidine and covered with a sterile dressing. The catheter has been left in situ for up to two and a half days. After this time femoral artery puncture has been used when required.

Blood samples of about $1.5 \mathrm{ml}$. were taken under sterile and anaerobic conditions with a syringe, the dead space of which had been filled with heparin saline. A metal washer incorporated in the syringe provided a means of stirring. The syringe was capped and kept on ice until analysis which was done within one hour. $\mathrm{O}_{2}$-content was measured in duplicate or triplicate with the Roughton-Scholander syringe technique. $\mathrm{O}_{2}$-capacity was either measured in the same way, after equilibrating the sample for 10 minutes with air, or more usually by measuring the $\mathrm{Hb}$ concentration in a photoelectric colorimeter which was regularly checked against an iron standard. For the ratio $\left(\mathrm{O}_{2}\right.$ capacity in vol. \%) $\div$ ( $\mathrm{Hb}$ in $\mathrm{g} . \%$ ), 13 samplings of foetal blood gave a mean value of 1.33 (range $1 \cdot 31-1 \cdot 36$ ); 10 samplings of adult blood gave a mean value of 1.35 (range $1 \cdot 33$ $1 \cdot 38$ ). We therefore took $1 \cdot 34 \mathrm{vol}$. as the combining power of $1 \mathrm{~g}$. $\mathrm{Hb}$ (this value includes the physically dissolved $\mathrm{O}_{2}$ ). Percentage saturation was expressed simply as $100 \times\left(\mathrm{O}_{2}\right.$-content of sample $) \div\left(\mathrm{O}_{2}\right.$-content of sample equilibrated with air).

$p \mathrm{H}$ was measured with the Astrup apparatus (Astrup, Jørgensen, Andersen and Engel, 1960), correcting for temperature by adding 0.0147 for each ${ }^{\circ} \mathrm{C}$. the body temperature was below $37^{\circ} \mathrm{C}$. (Rosenthal, 1948). By using this apparatus to measure the change in $p \mathrm{H}$ after the sample has been equilibrated with $4 \%$ and $8 \% \mathrm{CO}_{2}$ in $\mathrm{O}_{2}$, the $\mathrm{PCO}_{2}$ and the standard bicarbonate concentration can be derived by means of a nomogram. Throughout this paper plasma bicarbonate concentration implies standard bicarbonate $\left(\left[\mathrm{HCO}_{3}{ }^{-}\right]\right.$measured at a standard $\mathrm{PCO}_{2}$ of $40 \mathrm{~mm}$. $\mathrm{Hg}$ ), which we have chosen as the most appropriate measure of metabolic acidosis or alkalosis.

\section{Measurement of Shunt}

If the $\mathrm{O}_{2}$-capacity of blood equilibrated with air at 
TABLE 1

CALCULATION OF FACTOR $\mathrm{f}$ (EQUATION 1) FOR BLOOD EQUILIBRATED WITH GASES OF VARYING $\mathrm{O}_{2}$-TENSION

\begin{tabular}{|c|c|c|c|c|c|c|c|}
\hline Gas & & $\begin{array}{c}\text { Temperature } \\
\text { C. }\end{array}$ & $\begin{array}{c}\mathrm{Po}_{2} \\
(\mathrm{~mm} . \mathrm{Hg})\end{array}$ & $\begin{array}{c}\text { Adult or } \\
\text { Foetal Blood }\end{array}$ & $\mathrm{O}_{2}$-capacity & $\mathrm{O}_{2}$-content & $\begin{array}{c}100 \\
\mathrm{f}\end{array}$ \\
\hline $\begin{array}{cccc}100 \% & \mathrm{O}_{2} & & \\
96 \% & \mathrm{O}_{2}, & 4 \% & \mathrm{CO}_{2} \\
96 \% & \mathrm{O}_{2} & 4 \% & \mathrm{CO}_{2} \\
92 \% & \mathrm{O}_{2}, & 8 \% & \mathrm{CO}_{2} \\
60 \% & \mathrm{O}_{2}, & 40 \% & \mathrm{~N}_{2}\end{array}$ & \begin{tabular}{l|}
$\cdots$ \\
$\cdots$ \\
$\cdots$ \\
$\cdots$
\end{tabular} & $\begin{array}{l}37 \\
37 \\
37 \\
37 \\
19\end{array}$ & $\begin{array}{l}713 \\
685 \\
695 \\
665 \\
452\end{array}$ & $\begin{array}{l}\mathbf{A} \\
\mathbf{F} \\
\mathbf{F} \\
\mathbf{F} \\
\mathbf{F}\end{array}$ & $\begin{array}{l}22 \cdot 80 \\
18 \cdot 14 \\
20 \cdot 27 \\
20 \cdot 27 \\
20 \cdot 27\end{array}$ & $\begin{array}{l}24 \cdot 85 \\
20 \cdot 09 \\
22 \cdot 14 \\
22 \cdot 06 \\
21 \cdot 89\end{array}$ & $\begin{array}{l}100 / 97 \cdot 9 \\
100 / 97 \cdot 1 \\
100 / 97 \cdot 9 \\
100 / 97 \cdot 9 \\
100 / 98 \cdot 8\end{array}$ \\
\hline & & & & \multicolumn{4}{|c|}{ Mean $100 / 97 \cdot 9$} \\
\hline
\end{tabular}

room temperature and a $\mathrm{Po}_{2}$ of $150 \mathrm{~mm} . \mathrm{Hg}$ is $\mathrm{Co}_{2}$, then its $\mathrm{O}_{2}$-content when equilibrated with a gas at some higher $\mathrm{Po}_{2}$ and any given temperature will be given by, $\mathrm{O}_{2}$-content $=\frac{100}{\mathrm{f}}\left(\mathrm{Co}_{2}-0 \cdot 71\right)+100 . \frac{\alpha}{760} \times \mathrm{Po}_{2} \ldots(1)$, where 0.71 is the amount of physically dissolved $\mathrm{O}_{2}$ in vol. \% at a $\mathrm{Po}_{2}$ of $150 \mathrm{~mm}$. and an average room temperature of $18^{\circ} \mathrm{C}$; ; and $\alpha$ is the solubility coefficient of $\mathrm{O}_{2}$ in $\mathrm{ml} . \mathrm{O}_{2} / \mathrm{ml}$. blood at $760 \mathrm{~mm}$. $\mathrm{Hg}$. A value for $\alpha$ at different temperatures is available (Dittmer and Grebe, 1958), extrapolating if necessary for temperatures below $20^{\circ} \mathrm{C}$.

The factor $100 / \mathrm{f}$ relates to the fact that the maximum $\mathrm{O}_{2}$-carrying potential of $\mathrm{Hb}$ is not completely taken up when, as $\mathrm{O}_{2}$-capacity is ordinarily measured, blood is equilibrated with air, since at a $\mathrm{Po}_{2}$ of $150 \mathrm{~mm}$. adult $\mathrm{Hb}$ is known to be significantly less than $100 \%$ saturated (Nahas, Morgan and Wood, 1952). Further, some $\mathrm{Hb}$ present in normal blood as carboxy- and met-Hb may be converted to $\mathrm{HbO}_{2}$ when blood is equilibrated with gas of high $\mathrm{Po}_{2}$. These and other factors affecting measurement of $\mathrm{O}_{2}$-capacity have been discussed in detail by Roughton, Darling and Root (1944).

In order to derive a value for $f$ appropriate to the conditions of this study, samples of foetal and adult blood were equilibrated in a tonometer with a series of gas mixtures containing from 60 to $100 \% \mathrm{O}_{2}$. The $\mathrm{Po}_{2}$ of the gas was calculated, the $\mathrm{O}_{2}$-capacity and $\mathrm{O}_{2}$-content of the samples were measured and the values inserted in equation (1), enabling $f$ to be calculated. Results are shown in Table 1.

The results are satisfactorily consistent, the value for f ranging between $97 \cdot 1$ and $98 \cdot 8$ with a mean of $97 \cdot 9$. This figure implies that the $\mathrm{O}_{2}$-capacity as measured represented only $97.9 \%$ of the full capacity for $\mathrm{O}_{2}$ carriage by $\mathrm{Hb}$ as attained under conditions of high $\mathrm{O}_{2}$-tension. Of the residual $2 \cdot 1 \%$ of unsaturation, $1 \cdot 2 \%$ would be accounted for if the amount of unsaturation of adult $\mathrm{Hb}$ at $\mathrm{Po}_{2} 150 \mathrm{~mm}$. (Nahas et al., 1952) obtains also for foetal $\mathrm{Hb}$. This would leave $0.9 \%$ of unsaturation to be accounted for by the other factors mentioned. In applying equation (1) we have throughout taken $f$ to have the value $97 \cdot 9$.

Alveolar $\mathrm{PO}_{2}$ was calculated from the alveolar air equation,

alveolar $\mathrm{Po}_{2}=\mathrm{FO}_{2}\left(\mathrm{~PB}_{\mathrm{B}}-\mathrm{PW}\right)-\mathrm{PCO}_{2}\left(\mathrm{Fo}_{2}+\frac{1-\mathrm{Fo}_{2}}{\mathrm{R}}\right) \ldots$

where $\mathrm{Fo}_{2}$ is the fraction of $\mathrm{O}_{2}$ in the inspired gas;
$\mathrm{P}_{\mathbf{B}}$ the barometric pressure in $\mathrm{mm}$. $\mathrm{Hg}$ and $\mathrm{PW}_{W}$ the water vapour pressure at body temperature; and $R$ the Respiratory Quotient, taken to be $0 \cdot 8 . \mathrm{PCO}_{2}$ in this equation is strictly alveolar $\mathrm{PCO}_{2}$, which under most conditions differs negligibly from arterial $\mathbf{P C O}_{2}$. Large R-L shunts (over $70 \%$ ) do cause arterial $\mathrm{PCO}_{2}$ appreciably to exceed alveolar values (Strang and MacLeish, 1961), although the effect on alveolar $\mathrm{PO}_{2}$ as calculated by equation (2) is unimportant under the conditions of this study, and no correction for it was therefore made.

Any admixture of unoxygenated blood with the blood coming from pulmonary capillaries causes a depression of $\mathrm{O}_{2}$-content of systemic arterial blood, and measurement of this depression enables the percentage of the heart output which is so shunted to be calculated, according to the shunt equation,

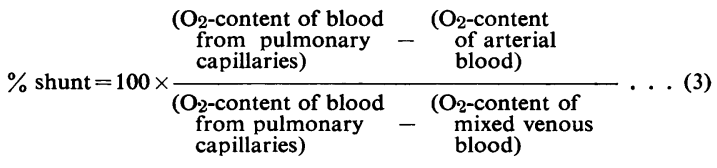

With high inspired $\mathrm{O}_{2}$-concentrations it can be assumed that blood leaving the pulmonary capillaries is fully saturated with $\mathrm{O}_{2}$ (see below), so that under these conditions alveolar $\mathrm{Po}_{2}$ being known (equation 2), the $\mathrm{O}_{2}$-content of pulmonary capillary blood can be calculated (equation 1). The $\mathrm{O}_{2}$-content of arterial blood is measured directly. The $\mathrm{O}_{2}$-content of mixed venous blood, however, cannot be measured in the newborn baby, because the possibility of shunting through the foramen ovale and ductus arteriosus would necessitate blood being sampled from pulmonary artery distal to the ductus. It is generally assumed that there is a difference of about $5 \mathrm{vol}$. \% between the $\mathrm{O}_{2}$-contents of arterial and mixed venous blood. Strang and MacLeish (1961) concluded that in their series of newborn infants with respiratory distress an arteriovenous difference of 4 vol. \% was applicable. Fortunately the value is not critical, since the denominator in equation (3) tends to be large compared with the numerator. We have throughout assumed a value of 5 vol. \% for the arteriovenous difference in $\mathrm{O}_{2}$-content. If now we put $\Delta$ for the difference between the $\mathrm{O}_{2}$-content of pulmonary capillary and arterial blood, equation (3) can be written simply as,

$$
\% \text { shunt }=\frac{100 \Delta}{\Delta+5}
$$


It should be noted that the percentage shunt can be calculated equally well whether the subject inspires $100 \%$ $\mathrm{O}_{2}$ (as is usual in estimating shunts), or any other known high concentration of $\mathrm{O}_{2}$. To be valid for this purpose the inspired $\mathrm{O}_{2}$-concentration must be sufficiently high to satisfy two requirements. (1) $\mathrm{Hb}$ must be virtually $100 \%$ saturated. For example, if $40 \% \mathrm{O}_{2}$ is inspired the alveolar $\mathrm{PO}_{2}$ will be $250 \mathrm{~mm}$. $\mathrm{Hg}$ and (adult) $\mathrm{Hb}$ will be $99.65 \%$ saturated. If $50 \% \mathrm{O}_{2}$ is inspired alveolar $\mathrm{Po}_{2}$ will be $315 \mathrm{~mm}$. and $\mathrm{Hb}$ will be $99.9 \%$ saturated. (2) Blood leaving pulmonary capillaries must be fully oxygenated. There are both theoretical and clinical grounds for the view that arterial unsaturation due to pulmonary defect, whether one of diffusion, distribution or ventilation, is highly sensitive to small rises in inspired $\mathrm{O}_{2}$-concentration (Shepard, 1958; Perkins, Adams, Flores, Harper and Landahl, 1958; Campbell, 1960). Because of this fact, a failure under resting conditions to achieve normal saturation with levels of inspired $\mathrm{O}_{2}$ of about $40 \%$, implies the presence of some degree of R-L shunt. (A pulmonary defect so gross that blood flows through some parts of lung without appreciable gas exchange acts as a shunt.)

In order to test the validity of our methods and of the various assumptions made in calculating shunts, we have in 10 instances compared the shunt calculated for an infant inspiring (1) $100 \% \mathrm{O}_{2}$, and (2) from 40 to $80 \%$ $\mathrm{O}_{2}$. Results are set out in Table 2, and show that there is fair agreement in most instances between shunt values when calculated at two levels of inspired $\mathrm{O}_{2}$.

We conclude that it is practicable to calculate the size of shunt for any infant in whom $\mathrm{O}_{2}$-capacity and -content are known, when $\mathrm{O}_{2}$ at not less than $40-50 \%$ is breathed. Shunts in distressed infants are often large, making a moderate degree of error acceptable.

\section{Results}

Premature Infants without Respiratory Distress. Amongst the infants studied were some who during
TABLE 2

SHUNT CALCULATED AT TWO LEVELS OF INSPIRED OXYGEN

\begin{tabular}{|c|c|c|c|c|}
\hline \multirow{2}{*}{$\begin{array}{l}\text { Case } \\
\text { No. }\end{array}$} & \multirow{2}{*}{$\begin{array}{c}\text { Age } \\
\text { (hrs) }\end{array}$} & \multirow{2}{*}{$\begin{array}{l}\text { Respiratory } \\
\text { Symptoms }\end{array}$} & \multicolumn{2}{|c|}{$\%$ Shunt } \\
\hline & & & $\begin{array}{l}\text { 1. Inspiring } \\
100 \% \mathrm{O}_{2}\end{array}$ & $\begin{array}{l}\text { 2. Inspiring } \\
<100 \% \mathrm{O}_{2}\end{array}$ \\
\hline $\begin{array}{r}14 \\
13 \\
15 \\
15 \\
16 \\
17 \\
11 \\
11 \\
9 \\
8\end{array}$ & $\begin{array}{c}2 \frac{1}{2} \\
2 \frac{1}{2} \\
4 \\
16 \\
4 \frac{1}{2} \\
5 \\
8 \\
28 \\
11 \\
11\end{array}$ & $\begin{array}{l}+++ \\
+ \\
++ \\
++ \\
+++ \\
+ \\
++ \\
++ \\
+ \\
+\end{array}$ & $\begin{array}{r}32 \\
10 \\
21 \\
26 \\
20 \\
24 \\
15 \\
18 \\
9 \\
13\end{array}$ & $\begin{array}{r}35 \text { (with } 80 \% \mathrm{O}_{2} \text { ) } \\
3 \text { (with } 56 \% \mathrm{O}_{2} \text { ) } \\
25 \text { (with } 50 \% \mathrm{O}_{2} \text { ) } \\
34 \text { (with } 70 \% \mathrm{O}_{2} \text { ) } \\
33 \text { (with } 46 \% \mathrm{O}_{2} \text { ) } \\
25 \text { (with } 68 \% \mathrm{O}_{2} \text { ) } \\
13 \text { (with } 60 \% \mathrm{O}_{2} \text { ) } \\
18 \text { (with } 50 \% \mathrm{O}_{2} \text { ) } \\
16 \text { (with } 48 \% \mathrm{O}_{2} \text { ) } \\
15 \text { (with } 40 \% \mathrm{O}_{2} \text { ) }\end{array}$ \\
\hline
\end{tabular}

the first few hours of life had tachypnoea, brief apnoeic spells or expiratory moan. These symptoms were at no time accompanied by laboured breathing or rib recession, and they disappeared during the course of 24 to 36 hours. Ten such infants were studied, all were premature, nine weighing less than $1.9 \mathrm{~kg}$. The arterial $\mathrm{PCO}_{2}$ in this group was normal or low, ranging from 24 to $44 \mathrm{~mm}$. $\mathrm{Hg}$ at the time of the measurements, which were made some time during the first 16 hours of life. Although, therefore, these infants were studied because initially they presented as possible early cases of RDS, their subsequent course gave no evidence of pulmonary disorder. Findings in this group (Fig. 1) thus provide a baseline by which to judge the findings in infants with respiratory distress.

Arterial $\mathrm{O}_{2}$-saturation measured in eight cases while breathing air was $94 \%$ or more, and in the remaining two cases while breathing $40-45 \% \quad \mathrm{O}_{2}$ was $98 \%$ or more.

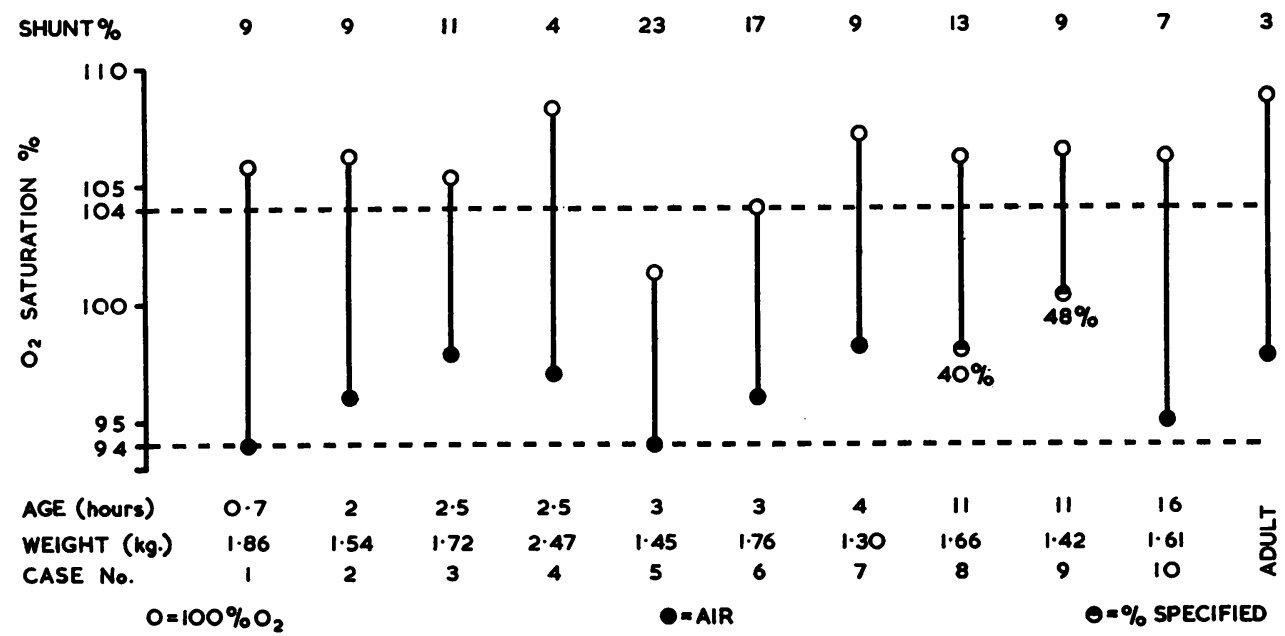

FIG. 1.-Arterial saturation of 10 premature infants, aged 0.7-16 hours, breathing air (or $40-45 \%$ oxygen) and breathing $100 \%$ oxygen, with R-L shunt values. Normal adult shown for comparison. 

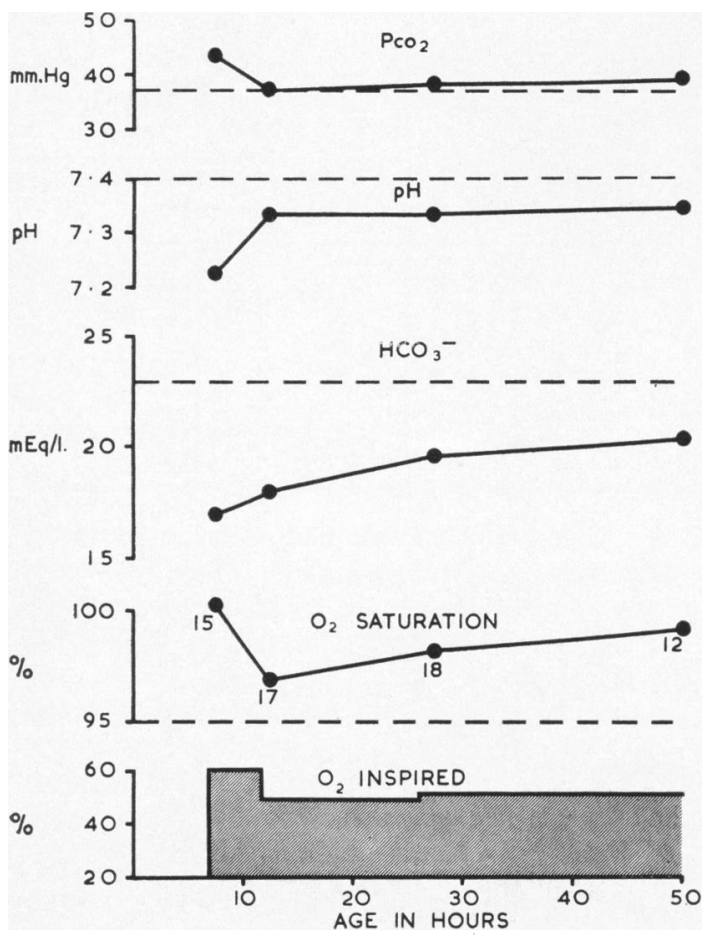

FIG. 2.-(Case 11.) Moderately severe respiratory distress syndrome. Dotted lines indicate average normal values-arterial $\mathbf{P C O}_{2} 37 \mathrm{~mm}$. $\mathrm{Hg}, p \mathrm{H} 7 \cdot 4$, standard bicarbonate $23 \mathrm{mEq} / 1$., $\mathrm{O}_{2}$-saturation $95 \%$. The figures below the $\mathrm{O}_{2}$-saturation graph give the $\%$ R-L shunt.

Pure $\mathrm{O}_{2}$ was then administered by means of a face mask, with a flow rate of $51 . / \mathrm{min}$. A steady state was considered to have been reached after 10 minutes, Strang and MacLeish (1961) having shown that in normal newborns under these conditions one minute suffices to wash out nitrogen from the lungs. Arterial $\mathrm{O}_{2}$-saturation while breathing pure $\mathrm{O}_{2}$ was from $104 \%$ to $108 \cdot 2 \%$ (Fig. 2). From these data R-L shunts were calculated. In the majority of this group of 'normal' prematures the shunt values lay between 7 and $11 \%$ (seven out of 10 cases), with a range from 4 to $23 \%$ and a mean of $10 \cdot 6 \%$. For comparison similar data for an adult are shown, with a shunt value of $3 \%$.

Infants with Respiratory Failure. In any case of respiratory failure much information as to the type of respiratory disorder present can be derived from a knowledge of (i) the arterial $\mathrm{O}_{2}$-saturation in relation to the concentration of $\mathrm{O}_{2}$ breathed, and (ii) the arterial $\mathrm{PCO}_{2}$. Such information in turn provides some theoretical basis for planning treatment.
To illustrate this approach, we have chosen three cases of RDS, graded as moderately severe, severe, and very severe. In each case the course of the illness is traced in terms of the $\mathrm{O}_{2}$-saturation, percentage R-L shunt, $p \mathrm{H}, \mathrm{HCO}_{3}{ }^{-}$and $\mathrm{PCO}_{2}$.

Case 11. (Fig. 2.) A full-term baby of $2.62 \mathrm{~kg}$. born normally at home. He breathed without delay, but over the next hour became increasingly cyanosed. At 2 hours he collapsed and stopped breathing, but was revived by mouth-to-mouth breathing. He reached hospital at 6 hours, when respiration was slow and gasping, and cyanosis severe. Oxygen was given, at first with intermittent positive pressure by mask, then into an incubator. The colour rapidly returned to normal, and breathing became regular but rapid (78-100 per min.) with expiratory moan and rib recession. Air entry was very poor, particularly over the left lung. A radiograph showed an enlarged heart, and groundglass opacity of the lungs, more marked on the left. Clinically, therefore, he now presented the typical picture of RDS.

His colour remained normal while breathing $\mathrm{O}_{2}$ at about $40 \%$, but every time the $\mathrm{O}_{2}$-concentration was reduced to that of air, respiratory distress increased seriously and marked cyanosis reappeared. The breathing remained distressed for 48 hours, after which his $\mathrm{O}_{2}$-dependence lessened, although a week elapsed before $\mathrm{O}_{2}$ could be entirely omitted.

Reference to Fig. 2 shows that initially at 8 hours there was a moderate metabolic acidosis $\left(\mathrm{HCO}_{3}{ }^{-} 17 \mathrm{mEq}\right)$ reflecting the six-hour period of hypoxia before reaching hospital; the bicarbonate level tended to correct itself over the next 40 hours. The $\mathrm{PCO}_{2}$ was virtually normal throughout. The $\mathrm{O}_{2}$-saturation, measured in an ambient $\mathrm{O}_{2}$-concentration of $48-60 \%$, was always in the high-normal range between $97 \%$ and $100 \cdot 3 \%$. R-L shunt values varied between 12 and $18 \%$, values which are not outside the range for 'normal' prematures (Fig. 1).

Summary: RDS of moderate severity, characterized by an $\mathrm{O}_{2}$-responsive hypoxia; a small $\mathrm{R}-\mathrm{L}$ shunt (less than $20 \%$ ); and the absence of hypercapnia.

Case 12. (Fig. 3.) A baby of $2 \cdot 86 \mathrm{~kg}$. delivered by caesarean section after labour had begun at 36 weeks and become complicated by transverse arrest. He breathed without delay, but within half an hour he had developed rapid laboured breathing with moaning and recession. By 4 hours cyanosis was marked, but was at this stage relieved by $35 \% \mathrm{O}_{2}$. Air entry was poor over both lungs, with generalized fine râles. A radiograph (on day 2) showed ground-glass opacity of both lungs.

Respiratory distress became steadily more severe over the next 48 hours, $O_{2}$-saturation falling from $96 \%$ to $91.5 \%$ despite the ambient $\mathrm{O}_{2}$ being gradually raised to $90 \%$ (Fig. 3). R-L shunt values were constant at $32-38 \%$ during this phase. At the same time the $\mathrm{PCO}_{2}$ rose steadily to a maximum of $70 \mathrm{~mm}$. With a view to compensating the acidosis, mainly respiratory, $\mathrm{NaHCO}_{3}$ was given by intravenous drip, $65 \mathrm{ml} . / \mathrm{kg}$./day of a solu- 

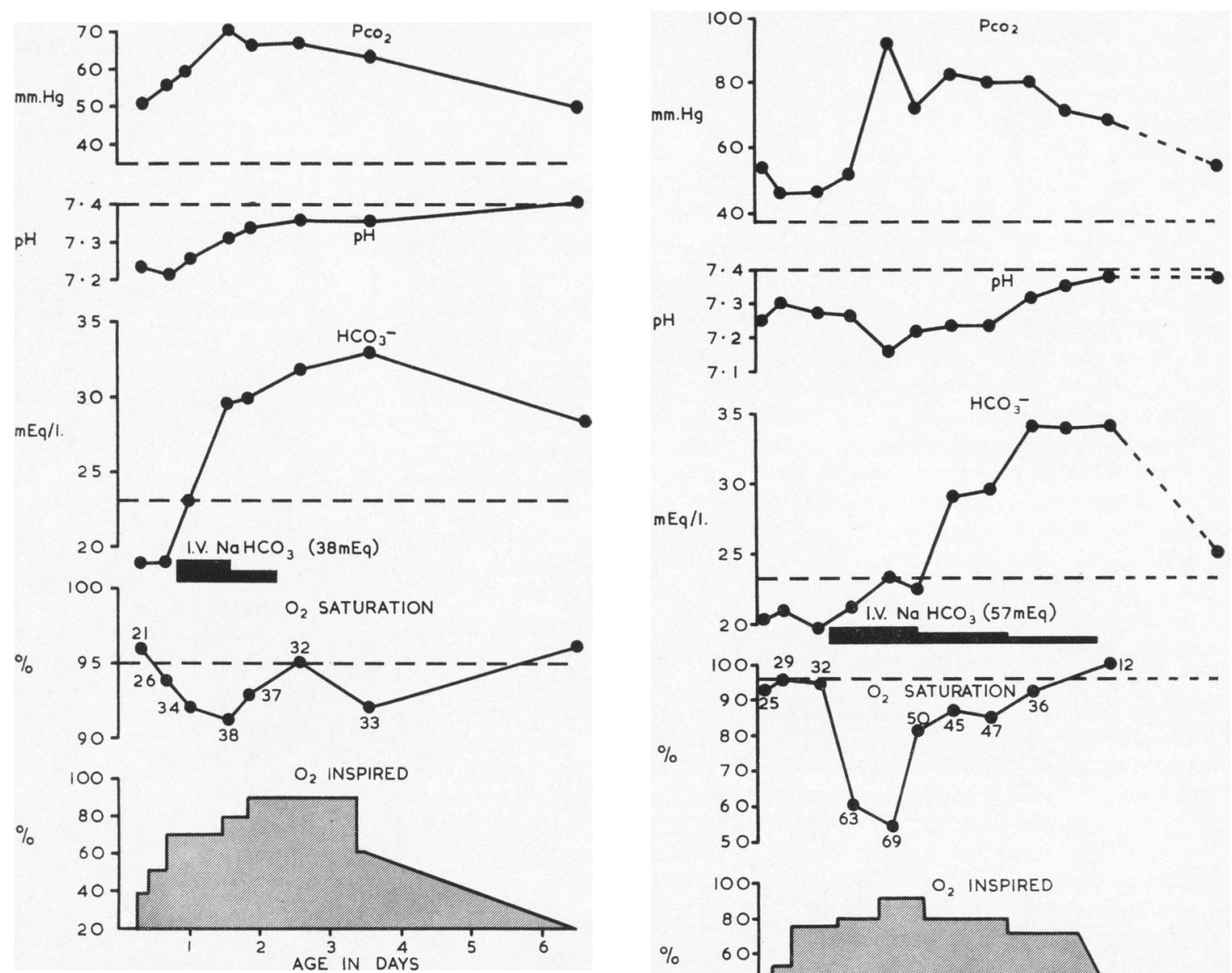

Fig. 3.-(Case 12.) Severe respiratory distress syndrome (see legend to Fig. 2).

tion of $\mathrm{NaHCO}_{3} 100 \mathrm{mEq} / \mathrm{l}$. in $10 \%$ glucose, reducing the strength of the $\mathrm{NaHCO}_{3}$ successively after 20 hours. The plasma $\mathrm{HCO}_{3}$ thereby rose from 19 to $33 \mathrm{mEq} / \mathrm{l}$. and the $p \mathrm{H}$ from $7 \cdot 2$ to $7 \cdot 4$. Improvement began on day 4 and by day 7 the baby was able to maintain normal $\mathrm{O}_{2}$-saturation in air.

Summary: RDS of severe degree with recovery characterized by moderate R-L shunt (about 35\%); an $\mathrm{O}_{2}$-saturation which could be maintained at $90-95 \%$ by giving $\mathrm{O}_{2}$ up to $90 \%$; and considerable hypercapnia.

Case 13. (Fig. 4.) Born at 37 weeks gestation by elective caesarean section for maternal diabetes, weight $2.84 \mathrm{~kg}$. He breathed without delay, but by 40 minutes when investigations were begun, breathing had become slightly laboured, with some recession and moaning. By 6 hours respiratory distress was already severe, and cyanosis could only be prevented by raising the ambient $\mathrm{O}_{2}$ to $50 \%$ (Fig. 4). By day 2 respiratory distress was extreme, and cyanosis was now present even in $90 \% \mathrm{O}_{2}$, arterial saturation falling to a low level of $53 \%$, at which stage $\mathrm{PCO}_{2}$ had risen to $92 \mathrm{~mm}$. Intravenous $\mathrm{NaHCO}_{3}$
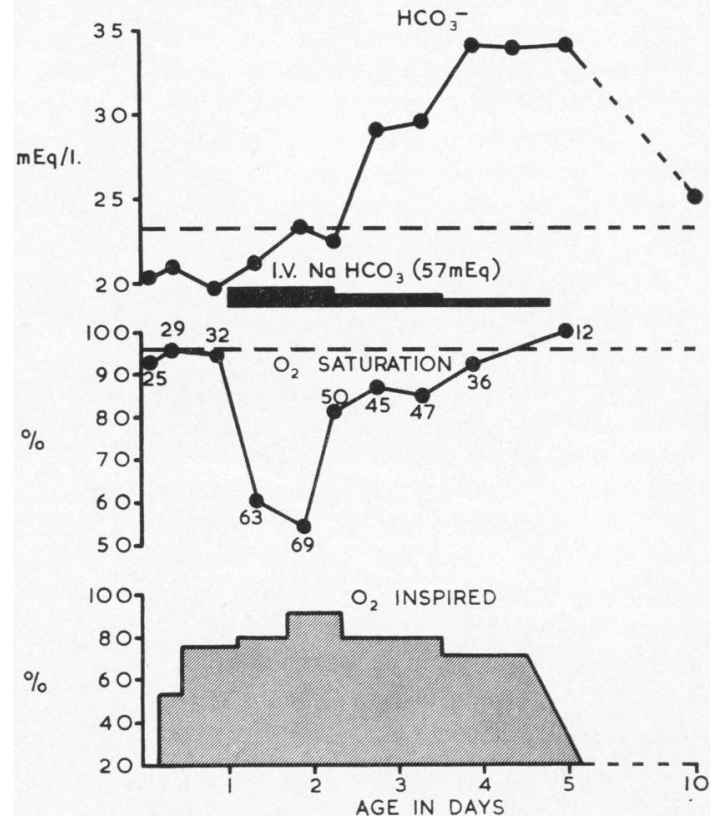

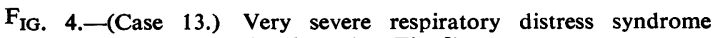
(see legend to Fig. 2).

was given under the same scheme as for Case 12, in order to correct the acidosis, mainly respiratory (lowest $p \mathrm{H}$ 7-18). Throughout the first four days he remained desperately ill, but by day 5 he was able to tolerate successive lowering of the ambient $\mathrm{O}_{2}$ concentration, respiration gradually returning to normal by about day 10 .

Summary: RDS of extreme severity with recovery in the infant of a diabetic mother, characterized by large R-L shunt (about $70 \%$ ); an $\mathrm{O}_{2}$-saturation below $60 \%$ even in $90 \% \mathrm{O}_{2}$; and severe hypercapnia.

\section{Discussion}

R-L Shunt in the Newborn. It is known that in normal adults there is a small R-L shunt amounting to about $2 \%$ of the cardiac output, resulting from shunts through the bronchial and Thebesian veins. No comparable information exists for the normal 
infant. The data shown in Fig. 1 refer to premature infants in the first 16 hours of life. These infants showed only slight and transient symptoms, while respiratory function, as judged by arterial $\mathrm{O}_{2^{-}}$ saturation and $\mathrm{PCO}_{2}$, was good. The data may therefore be useful as a guide to the level of shunt to be expected in healthy premature infants.

The mean value for R-L shunt was $10.6 \%$, seven of the 10 cases gave values between 7 and $11 \%$, and the highest value was $23 \%$. No great accuracy can be claimed for these figures, since at these low levels of shunt an error in measuring $\mathrm{O}_{2}$-content of only 0.1 vol. $\%$ will alter the shunt value by $2 \%$. That they are reasonably correct, nevertheless, is suggested by the fact that using the same technique a normal adult gave a shunt value of $3 \%$.

A comparison of these findings can be made with those for normal newborns by using some data provided by Graham (1959), who measured the $\mathrm{Po}_{2}$ of arterial blood in infants 3-50 hours old, while breathing $50 \% \mathrm{O}_{2}$. The mean value for arterial $\mathrm{PO}_{2}$ was $153 \mathrm{~mm}$. $\mathrm{Hg}$, compared with an alveolar $\mathrm{Po}_{2}$ of $317 \mathrm{~mm}$. (as calculated by equation (2)), giving a difference between alveolar and arterial $\mathrm{O}_{2}$-tensions of $168 \mathrm{~mm}$. This figure corresponds to an $\mathrm{O}_{2}$-content difference of $0.52 \mathrm{vol}$. $\%{ }^{*}$ between pulmonary capillary blood and arterial blood, and to a shunt value (equation 4 ) of $9 \cdot 4 \%$. This figure for the R-L shunt in normal newborns is about the same as the mean of $10.6 \%$ arrived at for the prematures studied.

Besides the anatomical sites available in the adult for R-L shunts, the newborn infant possesses also the ductus arteriosus and the foramen ovale. Oliver, Demis and Bates (1961) studying infants in the first hour of life, found L-atrial blood to have a higher $\mathrm{Po}_{2}$ than arterial (aortic) blood, and concluded that this must be due to some R-L shunting through the ductus, a conclusion compatible with the bidirectional flow through the ductus noted by James (1959) in infants in the first hour of life.

R-L shunting through the foramen ovale is also probably the rule for normal infants during the first few days of life, as was shown originally by Lind and Wegelius (1954) by means of angiocardiography, and reported recently by Stahlman, Merrill, Lequire and James (1961) using an ingenious dyedilution technique.

Thus R-L shunting occurs in the newborn infant at a number of sites outside the lungs, and this could account for the shunt values observed. Whether in addition there is an intrapulmonary shunt is not known.

\footnotetext{
* Since physically dissolved $\mathrm{O}_{2}$ increases by 0.00312 vol. $\%$ for each mm. $\mathrm{Hg}$ rise in $\mathrm{Po}_{2}$ (Sendroy, Dillon and Van Slyke, 1934).
}

The Pulmonary Defect in Respiratory Distress Syndrome. Comparing a series of cases of RDS of graded severity such as Cases 11,12 and 13, the findings range from the case of moderate severity, where there is an $\mathrm{O}_{2}$-responsive hypoxia, a small shunt and no hypercapnia, to the severe case where there is $\mathrm{O}_{2}$-unsaturation even in high $\mathrm{O}_{2}$-concentration, a very large R-L shunt and gross hypercapnia.

If the same type of pulmonary defect is responsible for both moderate and severe forms of RDS, then a distribution defect would seem to cover the facts best. A distribution defect of the kind where a proportion of alveoli are non-perfused will at first lead to an increase in functional dead space, with an $\mathrm{O}_{2}$-sensitive hypoxia, but no $\mathrm{CO}_{2}$ retention, the pattern seen in Case 11. $\mathrm{CO}_{2}$ retention is here absent because a small increase in ventilation suffices to remove any excess $\mathrm{CO}_{2}$ via well-functioning alveoli. Further increase in the proportion of non-perfused alveoli will eventually lead to functional dead space approaching tidal volume. Removal of excess $\mathrm{CO}_{2}$ being limited by the capacity to increase ventilation, $\mathrm{CO}_{2}$ now accumulates.

This conclusion is in accord with the rather scanty facts available from earlier studies. An increase in functional dead space was the most prominent fault in respiratory function found by Karlberg, Cook, O'Brien, Cherry and Smith (1954) in their study of respiratory function in RDS; the ratio of functional dead space to tidal volume averaged 0.66 in three distressed infants, against 0.32 in normals. Nelson, Prod'hom, Lipsitz, Cherry and Smith (1961), whose study included measurement of alveolararterial gradients for $\mathrm{O}_{2}$ and $\mathrm{CO}_{2}$, concluded that a severe degree of non-perfusion of alveoli was a prominent feature of these cases.

In addition, in the severe cases of RDS there is a large R-L shunt which may amount to $60 \%$ or more, as was pointed out by Strang and MacLeish (1961) and confirmed in our cases. The site of this shunt is at present not known. Rudolph and co-workers (Rudolph, Drorbaugh, Auld, Rudolph, Nadas, Smith and Hubbell, 1961) catheterized a series of distressed infa tts, studying particularly the question of shunts through the ductus arteriosus. In their cases with severe RDS a large L-R ductal shunt was the most conspicuous feature; in some cases a concomitant R-L ductal shunt was also observed, but in only one of the 10 severe cases studied was this judged to be large. This infant while breathing pure $\mathrm{O}_{2}$ gave a saturation of $80 \%$ in L-atrial blood and $63 \%$ in aortic blood. We have calculated that these figures imply that there was a 'pre-ductal' R-L shunt (through foramen 
ovale and/or lungs) of $50 \%$, and one of $12 \%$ through the ductus. The only facts bearing on the foramen ovale as the site of R-L shunting is a brief comment by Stahlman (1961) that such a shunt is demonstrable by dye-dilution techniques in normal newborns, and that in distressed newborns this 'may be increased'.

There is thus not much evidence to suggest that the very large amount of blood R-L shunted in these cases all by-passes the lungs via the ductus and foramen ovale, although doubtless much of it does so. It seems probable that a considerable part of the shunt must be intrapulmonary, much of the blood which flows through the lungs making no contact with functioning alveoli. A diffusion defect, even if severe, is hardly compatible with the findings, because with such a defect $\mathrm{O}_{2}$-saturation is very sensitive to inspired $\mathrm{O}_{2}$ concentration, and we have found that the shunt effect in distressed infants is in general not less when breathing pure $\mathrm{O}_{2}$ than when breathing $40-80 \% \mathrm{O}_{2}$ (Table 2).

To summarize conclusions, then, in RDS findings would be compatible with a distribution defect, whereby much of the inspired air goes to nonperfused alveoli and much of the perfusing blood goes to non-ventilated alveoli. Such a gross functional disturbance of the lungs is, of course, in keeping with the evidence of a similarly gross lung disorder obtained by auscultation (deficient air entry), by radiology (generalized mottling or groundglass opacity of lungs) and, in fatal cases, by histology (extensive atelectasis with or without hyaline membrane).

Principles of Oxygen Therapy in RDS. When the infant's needs for $\mathrm{O}_{2}$ are being considered, the brain is usually thought of as the organ for which a good supply of $\mathrm{O}_{2}$ is most essential. Yet the brain can function reasonably well with quite low $\mathrm{O}_{2}$-tensions, as is clear from the normal development of the nervous system in many infants with cyanotic heart disease. Oxygenation of the respiratory muscles, however, may be crucial for the infant with RDS, in that its survival may depend upon whether or not the respiratory muscles can continue to ventilate the lungs throughout the critical days when the illness is at its height. Some discussion of the work of breathing is therefore relevant.

The work of breathing in the normal infant at rest has been calculated to be much the same as for the adult, about $1 \%$ of the basal metabolism (Cook, Sutherland, Segal, Cherry, Mead, McIlroy and Smith, 1957). It is obvious from watching any infant with severe RDS that the work of breathing must be very greatly increased. The conspicuous retraction of ribs and sternum demonstrates the abnormal resistance of the lungs to expansion (low compliance) (Cook et al., 1957). The respiratory rate of 80 or more reflects the effort to maintain a large minute volume in order to compensate for a large functional dead space (Karlberg et al., 1954).

The situation is somewhat analogous to the respiratory failure of the adult with advanced emphysema, where the increased work of breathing is also due in part to the need to compensate for a large functional dead space by increased ventilation. In these cases the work of breathing rises steeply as ventilation is increased, and the point is soon reached where ventilation cannot be further increased because the $\mathrm{O}_{2}$ cost of breathing is more than the extra $\mathrm{O}_{2}$ taken in (Campbell, 1958).

The only study in which an attempt was made to measure the work of breathing in infants with RDS is that of the Boston team, Karlberg et al. (1954) and Cook et al. (1957). They concluded that these infants may be expending four to 10 times the normal amount of energy on breathing, and pointed out that fatigue of the respiratory muscles might often be the cause of death.

These considerations lead to the conclusion that the aim of $\mathrm{O}_{2}$ therapy in RDS should be to maintain the $\mathrm{Po}_{2}$ of blood supplying the respiratory muscles (i.e. of aortic blood) at a 'high normal' level. As we have not measured $\mathrm{Po}_{2}$ we have aimed at maintaining $\mathrm{O}_{2}$-saturation at about $95-97 \%$, corresponding to a $\mathrm{PO}_{2}$ of $80-100 \mathrm{~mm}$. Fall in $\left[\mathrm{HCO}_{3}^{-}\right]$has been regarded as a measure of the accumulation of lactic acid from imperfectly oxygenated respiratory muscles.

We must now consider how the $\mathrm{O}_{2}$-saturation and $\mathrm{O}_{2}$-tension of arterial blood are related to the concentration of inspired $\mathrm{O}_{2}$. If there is no R-L shunt, then any $\mathrm{O}_{2}$-saturation present is due to pulmonary disorder and will largely disappear with a modest increase in the ambient $\mathrm{O}_{2}$ to $30-40 \%$, as already described.

The situation when a R-L shunt is present is most simply displayed by the graphs shown in Fig. 5.*

* The figures from which these graphs were constructed were derived as follows: Assuming a $\mathrm{PCO}_{2}$ of $40 \mathrm{~mm}$. and an R.Q. of $0 \cdot 8$, alveolar $\mathrm{PO}_{2}$ was calculated from equation (2) for different concentrations of inspired $\mathrm{O}_{2}$. Inserting these values in equation (1) (the correction factor $100 / \mathrm{f}$ was omitted) gave the corresponding $\mathrm{O}_{2}$-content of pulmonary capillary blood, the $\mathrm{O}_{2}$-capacity of which was taken as 20 vol. $\%$. The values so obtained for $\mathrm{O}_{2}$-content of pulmonary capillary blood, when inserted into equation (3) with an assumed arteriovenous $\mathrm{O}_{2}$-content difference of $5 \mathrm{vol} . \%$, enabled arterial $\mathrm{O}_{2}$-content and saturation to be calculated for any shunt value (Fig. 5a). From these $\mathrm{O}_{2}$-saturation values, corresponding values for $\mathrm{PO}_{2}$ (Fig. 5b) were read off from a standard $\mathrm{HbO}_{2}$ dissociation curve for adult blood (Severinghaus, 1958), data for foetal blood in that part of the curve lying above $95 \%$ saturation not being available. 


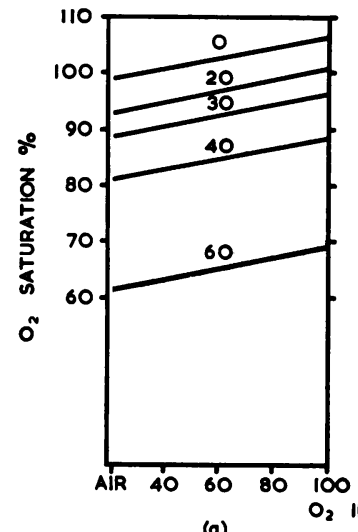

(a)

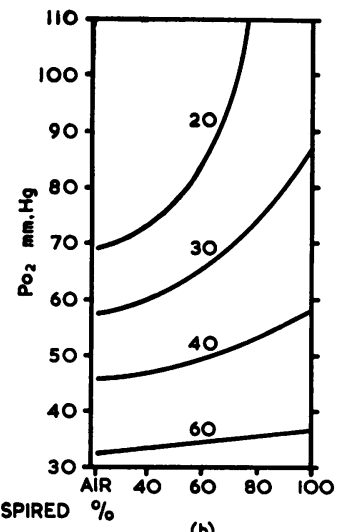

(b)

Fig. 5.-Effect of concentration of inspired oxygen on (a) arterial oxygen saturation, (b) oxygen tension $\left(\mathrm{PO}_{2}\right)$, at various levels of R-L shunt, as shown by curves for $0,20,30,40$ and $60 \%$ shunt.

These show that with moderate shunts, up to $30 \%$, $\mathrm{O}_{2}$-therapy is able to restore arterial $\mathrm{O}_{2}$-saturation to near normal, provided high concentrations are used. Thus for a $30 \%$ shunt, $\mathrm{O}_{2}$-saturation in air is about $88 \%$, and can be raised to $95 \%$ by breathing $90 \% \mathrm{O}_{2}$; the corresponding rise in $\mathrm{PO}_{2}$ is from $57 \mathrm{~mm}$. to $79 \mathrm{~mm}$. $\mathrm{Hg}$, a gain of $22 \mathrm{~mm}$. With a $60 \%$ shunt, however, saturation will be $61 \%$ in air, raised to $68 \%$ by breathing $90 \% \mathrm{O}_{2}$, but at this point in the S-shaped $\mathrm{HbO}_{2}$ dissociation curve the corresponding rise in $\mathrm{PO}_{2}$ is from 32 to $36 \mathrm{~mm}$., a gain of only $4 \mathrm{~mm}$.

The use of high concentrations of $\mathrm{O}_{2}$ up to $90 \%$ is seen to be fully justified in those cases where unsaturation is not abolished by lower levels of $\mathrm{O}_{2}$, always provided that high concentrations of inspired $\mathrm{O}_{2}$ are without toxic effects under these conditions (see later). Even with these high levels in the most severe cases (such as Case 13) the large shunt present will still make it impossible to achieve anything approaching normal oxygenation. Nevertheless, even though the gain in arterial $\mathrm{Po}_{2}$ may amount to only a few $\mathrm{mm}$. $\mathrm{Hg}$, this may yet be of significant help to the fatigued respiratory muscles.

In practice $\mathrm{O}_{2}$ needs will usually have to be gauged in terms of cyanosis. We have found that in newborn babies central cyanosis can be recognized when the saturation falls below about $85 \%$, which is well below the lowest level of $94 \%$ found in well prematures (Fig. 1). Saturations of $85 \%, 94 \%$ and $97 \%$ correspond to $\mathrm{Po}_{2}$ values (adult $\mathrm{Hb}$ ) of 52,73 and $100 \mathrm{~mm} . \mathrm{Hg}$. Thus $\mathrm{O}_{2}$ given at a concentration sufficient only to abolish cyanosis will give arterial $\mathrm{Po}_{2}$ levels far below either the normal or the optimum. As a working rule therefore $\mathrm{O}_{2}$ should be given at one-quarter higher concentration than the

minimum needed to abolish cyanosis. Thus, if there are signs of distress, but cyanosis is absent in air, $\mathrm{O}_{2}$ at about $25 \%$ should be given. If cyanosis is abolished by $40 \% \mathrm{O}_{2}$, then $50 \% \mathrm{O}_{2}$ should be given.

Oxygen Toxicity. A clear distinction must be drawn between the possible local toxic effects of $\mathrm{O}_{2}$ on the lungs, and the effects of $\mathrm{O}_{2}$ at high tension in arterial blood upon organs such as the eye. As regards the latter, retrolental fibroplasia was common at a period when premature babies were indiscriminately exposed for long periods to high ambient $\mathrm{O}_{2}$ concentrations, without regard to the resulting $\mathrm{O}_{2}$-tensions in the blood and tissues. The principles that we have suggested should govern $\mathrm{O}_{2}$ therapy, aim at maintaining a normal $\mathrm{O}_{2}$-tension in the blood, while in practice it is often impossible to attain a tension as high as this, however high the ambient $\mathrm{O}_{2}$ concentration. The danger of retrolental fibroplasia in infants given $\mathrm{O}_{2}$ according to this principle thus seems negligible on theoretical grounds, and no cases have been encountered.

The amount of danger (if any) to the lung itself of exposure to high $\mathrm{O}_{2}$ concentrations is much harder to define. In experimental animals exposure to $70-100 \% \quad \mathrm{O}_{2}$ for several days produces serious and often fatal lung lesions in the adult mouse, rat, rabbit, cat, dog and opossum. On the other hand the newborn of these species are very resistant to such damage and in them lung lesions can, in general (the guinea-pig is an exception), only be produced by combining exposure to $\mathrm{O}_{2}$ with vagotomy, intratracheal injections of foreign material, or other insult (Smith, Bennett, Heim, Thomson and Drinker, 1932; Tran Dinh De and Anderson, 1954; Berfenstam, Edlund and Zettergren, 1958; Patz, 1957; Buckingham and Sommers, 1959).

Less is known about the pulmonary effects in adult humans exposed to $\mathrm{O}_{2}$ (at normal barometric pressures). The best controlled study is that of Comroe and co-workers (Comroe, Dripps, Dumke and Deming, 1945), who exposed adult men for 24 hours continuously to $100 \% \mathrm{O}_{2}$. Most developed symptoms such as substernal discomfort or pain and cough, although symptoms were never severe enough to interfere with the experiment. The only functional effect discernible was some reduction of vital capacity. Exposure to $75 \% \quad \mathrm{O}_{2}$ likewise produced symptoms suggesting irritation of the respiratory passages, but $50 \% \quad \mathrm{O}_{2}$ was without effect. Clamann and Becker-Freyseng (1939) breathed $90 \% \mathrm{O}_{2}$ for 65 hours, ceasing then because one of the subjects became ill with vomiting. Both subjects showed some reduction in vital capacity. 
In human newborns, then, we need to know whether exposure to high $\mathrm{O}_{2}$ concentrations for many hours is liable to produce moderate symptoms as in adults, or gross lung lesions as in adult experimental animals, or no effects at all as in newborn animals. Unfortunately there are few facts with which to answer this important question. In the period after 1954, when the role of oxygen in retrolental fibroplasia became recognized, the suggestion was often made that oxygen might play a part also in causing the lung lesions found in newborns dying from respiratory failure. No evidence for this has appeared since that time, nor (so far as can be ascertained) has there been any striking fall in the incidence of RDS in the many centres where, since about 1954, the use of high $\mathrm{O}_{2}$ levels in nursing prematures has been greatly curtailed. Some have even suggested that the stricter use of oxygen was followed by some rise in mortality of prematures, and questioned whether this might not mean that infants with RDS needed more $\mathrm{O}_{2}$ than they had been receiving (Avery and Oppenheimer, 1960).

We have concluded that on present evidence the possible harmful effects of $\mathrm{O}_{2}$ on the lung do not outweigh the sound reasons that exist for using $\mathrm{O}_{2}$ in the amounts required to oxygenate the distressed infant adequately.

Correction of Acidosis. Usher (1961) focused attention on the importance of acidosis in RDS and considered that its correction by intravenous $\mathrm{NaHCO}_{3}$ with glucose increased survival rates. Some experimental support for this view came from Dawes and co-workers (Dawes, Mott and Stafford, 1960; Dawes and Shelley, 1961) who found that the length of time that foetal lambs survived complete asphyxia increased some threefold when acidosis was corrected by infusion of $\mathrm{Na}_{2} \mathrm{CO}_{3}$ with glucose, but not by the use of either alone.

Acid-base homeostasis inevitably breaks down in a severe case of RDS, where an initial respiratory acidosis, with later a superadded metabolic acidosis, is the rule. To correct this acidosis appears rational, in view of the wealth of evidence that a major departure from the normal $p \mathrm{H}$ interferes with many of the fundamental enzyme processes in the body. If the $p \mathrm{H}$ is falling we have infused intravenously $\mathrm{NaHCO}_{3} 100 \mathrm{mEq} / \mathrm{l}$. in $10 \%$ glucose at an initial rate of $65 \mathrm{ml} . / \mathrm{kg}$./day (Usher, 1961). The total amount of $\mathrm{NaHCO}_{3}$ given depends on serial $p \mathrm{H}$ measurements, so that in effect the baby is titrated to an arterial $p \mathrm{H}$ of about $7 \cdot 4$. To achieve this correction, an amount of $\mathrm{Na}$ may have to be given over 24-48 hours amounting to as much as half to two-thirds of the $\mathrm{Na}$ in the extracellular fluid (see
Cases 12, 13). As might be expected, therefore, oedema is sometimes a complication of this treatment, although this has not proved of serious import. Although the same fluid may occasionally be successfully given by gastric tube, most of the infants sufficiently ill to need this treatment fail either to retain or to absorb it by this route.

Where arterial specimens have not been available, $p \mathrm{H}$ has been measured on heel-prick blood, with sufficient accuracy for regulating the bicarbonate therapy.

Humidity. Babies with severe RDS still continue to inspire through the nose, so that air entering the lungs must be assumed (as in adults) to be saturated with water vapour at body temperature. Therefore humidification of the ambient air can have no effect upon the lungs. The same applies to the inhalation of aqueous mist, and this treatment was found to be without effect on the pulmonary disorder of infants with RDS by Silverman and Andersen (1956).

Humidification does, however, reduce the normal losses of water from skin and respiratory tract, particularly the latter (O'Brien, Hansen and Smith, 1954). Reduction of water loss in this way may be desirable, if, for instance, fluid intake is withheld for several days, but under different circumstances, such as when fluid is being given intravenously, it might not be desirable.

Under average nursery conditions with a humidity of $30-40 \%$, the newborn baby breathing quietly loses water via the respiratory tract at the rate of about $0.4 \mathrm{~g} . / \mathrm{kg}$./hour, and this loss may easily rise to $0.8 \mathrm{~g} . / \mathrm{kg}$./hour or more if the baby hyperventilates (Hooper, Evans and Stapleton, 1954; O'Brien et al., 1954). Eliminating this loss, as can be done by maximum humidification, is equivalent to cutting down the baby's heat losses by $0.5 \mathrm{cal}$./ $\mathrm{kg}$./hour,* which represents one quarter of its basal metabolism. Humidification must thus have the effect of enabling the distressed infant to maintain its body temperature while in an ambient temperature appreciably lower than would otherwise be the case (Silverman and Blanc, 1957). That the maintenance of a normal body temperature is of importance for survival seems probable on present evidence (Silverman, 1961).

Sternal Traction. We have laid particular emphasis on the work imposed on the respiratory muscles in RDS. A mechanical means of lightening this load would therefore be a logical form of treatment. A number of different mechanical solutions to the

\footnotetext{
* Since $1 \mathrm{ml}$. water evaporated at $37^{\circ} \mathrm{C}$. loses $0.58 \mathrm{cal}$.
} 


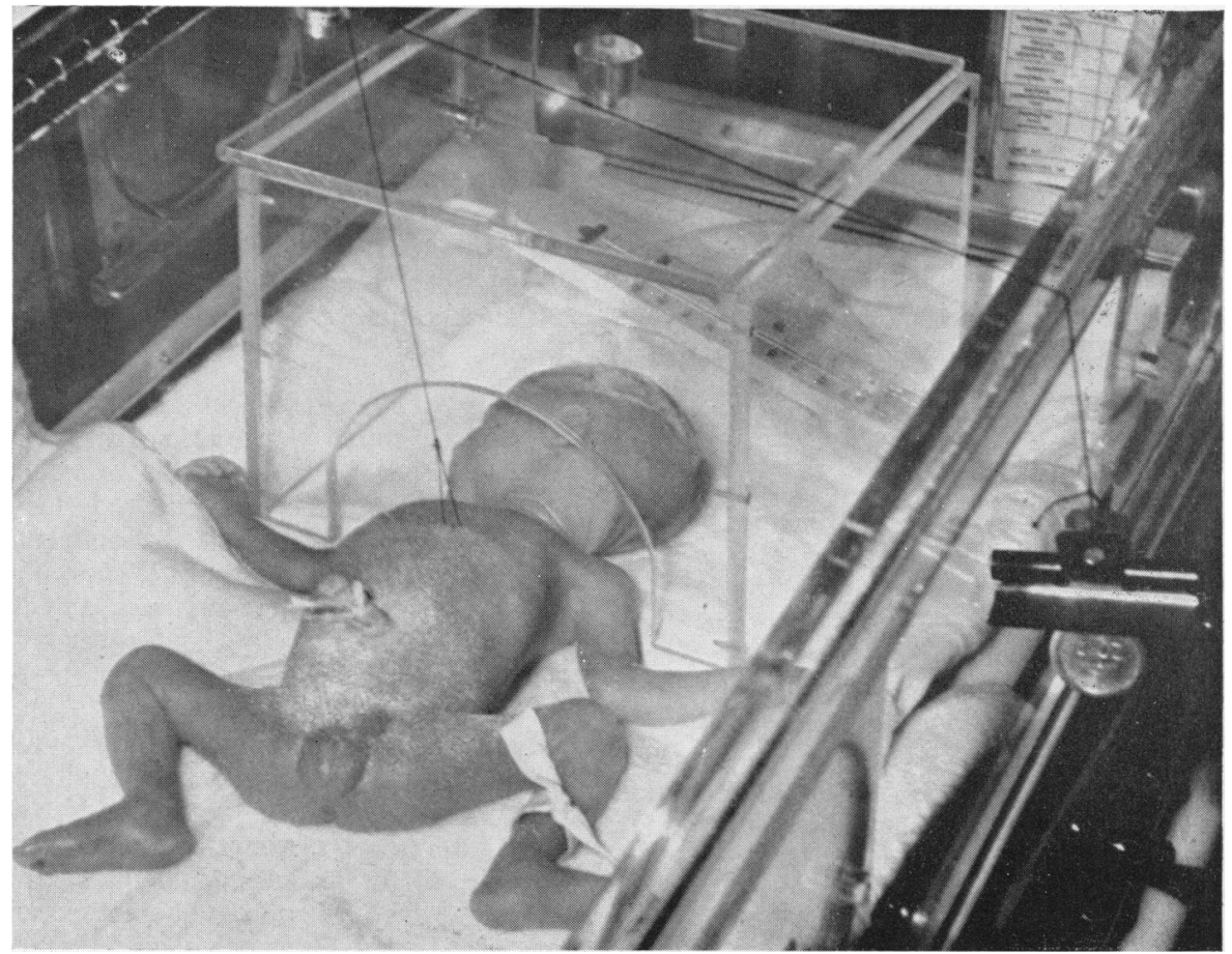

FIG. 6.-Sternal traction. The baby's weight was $950 \mathrm{~g}$. and the traction $50 \mathrm{~g}$.

problem have been tried (Donald and Lord, 1953; Benson, Celander, Haglund, Nilsson, Paulsen and Renck, 1958), but the only one of which we have experience is sternal traction (Love and Tillery, 1953; Michelson, 1953). It is applicable to those cases of RDS where marked in-drawing of the lower sternum accompanies each downward excursion of the diaphragm, as is seen especially in small prematures who, in addition to the stiff lungs typical of RDS, have a weak thoracic cage. Their situation can be likened to that of someone who is trying to pump a large volume of air using bellows with a defective framework lacking rigidity. When such bellows are forcibly opened to 'inspire' air the framework tends to collapse, so that only a fraction of the potential 'tidal air' of the bellows can be used. Despite the large amount of work expended by the operator in trying to compensate for the mechanical defect by working the bellows faster, the 'minute volume' he achieves is low.

The method we have used is to pass a suture behind the xiphisternum. The suture is taken through a hole in the roof of the incubator vertically above and is attached to a counter-weight (Fig. 6). The amount of traction is adjusted to give optimum relief to breathing; usually about $5 \%$ of the infant's weight is adequate, but as much as $10 \%$ of the body weight may be needed to stabilize the sternum, a useful demonstration of the magnitude of the muscular forces involved in respiration in distressed infants.

The immediate effect of applying such traction in a suitable case is to allow the exaggerated diaphragmatic excursion to be much reduced. In a small series of cases we have been impressed by the mechanical effectiveness of the method, and by the obvious relief it can bring to the infant.

\section{Summary and Conclusions}

By observing the course of the illness in infants with the respiratory distress syndrome, measuring serially the arterial $\mathrm{O}_{2}$-saturation, $\mathrm{PcO}_{2}, p \mathrm{H}$ and bicarbonate, the nature of the pulmonary disorder and its physiological consequences can be studied.

The right-to-left shunt in 'normal' premature infants is estimated to average $11 \%$. In severe respiratory distress the shunt increases as the illness progresses. The site of this shunt is discussed,

The work of the respiratory muscles in infants with respiratory distress is greatly increased, and 
survival may depend on the capacity of these muscles to maintain a high rate of work. To provide optimum conditions for the respiratory muscles to work in should, therefore, be the aim of treatment.

Oxygen therapy is discussed in terms of the oxygen concentration needed to restore normal arterial saturation. High concentrations up to $90 \%$ may be indicated. Oxygen toxicity is considered a lesser danger to the infant in respiratory failure than oxygen lack.

Acidosis, whether respiratory or metabolic, should be corrected by infusing sodium bicarbonate with glucose.

Humidification reduces water losses from the respiratory tract, and hence also reduces heat losses from the body. To this extent it may be of value.

Sternal in-drawing may be treated by sternal traction.

We received a great deal of help from Dr. E. J. Moran Campbell, Dr. Leonard B. Strang and Dr. Maureen Young. Sisters C. M. Bennett and J. G. Day, and Staff Nurses S. M. Dean and B. Cardwell, were responsible for the nursing of the babies. Mr. R. Flemans and Miss S. Tomlin gave invaluable technical assistance.

This work was supported by a research grant from the National Spastics Society, and by a grant towards equipment from The Dowager Countess Eleanor Peel Trust.

It is a pleasure to express our thanks to all these.

\section{REFERENCES}

Astrup, P., Jørgensen, K., Andersen, O. S. and Engel, K. (1960). The acid-base metabolism: a new approach. Lancet, 1, 1035.

Avery, M. E. and Oppenheimer, E. H. (1960). Recent increase in mortality from hyaline membrane disease. J. Pediat., 57, 553 .

Benson, F., Celander, O., Haglund, G., Nilsson, L., Paulsen, L. and Renck, L. (1958). 'Positive-pressure respirator treatment of severe pulmonary insufficiency in the newborn infant. Acta anaesth. scand., $2,37$.
and

Berfenstar, R., Edlund, T. and Zettergren, L. (1958). The hyaline membrane disease. A review of earlier clinical and experimental findirgs and some studies on the pathogenesis of hyaline membranes in $\mathrm{O}_{2}$-intoxicated rabbits. Acta paediat. (Uppsala), 47,82 .

Buckingham, S. and Sommers, S. C. (1959). Experimental pulmonary hyaline membranes induced pharmacologically. Fed. Proc., 18, 471.

Campbeli, E. J. M. (1958). The Respiratory Muscles and the Mechanics of Breathing. Lloyd-Luke, London.

(1960). Respiratory failure - the relation between oxygen concentrations of inspired air and arterial blood. Lancet, 2, 10 .

Clamann, H. G. and Becker-Freyseng, H. (1939). Cited by BeckerFreyseng, H. (1950). In German Aviation Medicine World War II, Vol. I, p. 502. U.S. Air Force, Washington.

Comroe, J. H., Dripps, R. D., Dumke, P. R. and Deming, M. (1945). Oxygen toxicity. J. Amer. med. Ass., 128, 710.

Cook, C. D., Sutherland, J. M., Segal, S., Cherry, R. B., Mead, J., Mcliroy, M. B. and Smith, C. A. (1957). Studies of respiratory physiology in the newborn infant. III. Measurements of mechanics of respiration. J. clin. Invest., 36, 440.

Dawes, G. S., Mott, J. C. and Stafford, A. (1960). Prolongation of survival in the anoxic foetal lamb. J. Physiol. (Lond.), 153, 16p. and Shelley, H. J. (1961). In Ciba Foundation Symposium on Somatic Stability in the Newly Born, ed. G. E. W. Wolstenholme and M. O'Connor, pp. 109, 110 . Churchill, London.

Dittmer, D. S. and Grebe, R. M. (1958). Handbook of Respiration, p. 7. Saunders, Philadelphia.
Donald, I. and Lord, J. (1953). Augmented respiration; studies in atelectasis neonatorum. Lancet, $1,9$.

Graham, B. D. (1959). Polarographic studies of $\mathrm{O}_{2}$ tension in newborn infants. Rep. 31st Ross Conference on Pediatric Research, p. 57, Columbus.

Hooper, J. M. D., Evans, I. W. J. and Stapleton, T. (1954). Resting pulmonary water loss in the newborn infant. Pediatrics, 13, 206.

James, L. S. (1959). The function of the ductus arteriosus and foramen ovale. Rep. 31st Ross Conference on Pediatric Research, p. 28, Columbus.

Karlberg, P., Cook, C. D., O'Brien, D., Cherry, R. B. and Smith, C. A. (1954). Studies of respiratory physiology in the newborn infant. II. Observations during and after respiratory distress. Acta paediat. (Uppsala), 43, Suppl. 100, 397.

Lind, J. and Wegelius, C. (1954). Human fetal circulation: changes in the cardiovascular system at birth and disturbances in the postnatal closure of the foramen ovale and ductus arteriosus. Cold Spr. Harb. Symp. quant. Biol., 19, 109.

Love, W. G. and Tillery, B. (1953). New treatment for atelectasis of the newborn. Amer. J. Dis. Child., 86, 423.

Michelson, R. P. (1953). Treatment of atelectasis in the newborn by sternal traction. Laryngoscope (St. Louis), 63, 379.

Nahas, G. G., Morgan, E. H. and Wood, E. H. (1952). Oxygen dissociation curve of arterial blood in men breathing high concentrations of oxygen. J. appl. Physiol., 5, 169.

Nelson, N. M., Prod'hom, L. S., Lipsitz, P. J., Cherry, R. B. and Smith, C. A. (1961). Ventilation and perfusion of the lung in normal infants and those with respiratory distress. Amer. $J$. Dis. Child., 102, 517 .

O'Brien, D., Hansen, J. D. L. and Smith, C. A. (1954). Effect of supersaturated atmospheres on insensible water loss in the newborn infant. Pediatrics, 13, 126.

Oliver, T. K., Jr., Demis, J. A. and Bates, G. D. (1961). Serial bloodgas tensions and acid-base balance during the first hour of life in human infants. Acta paediat. (Uppsala), 50, 346.

Patz, A. (1957). The role of oxygen in retrolental fibroplasia. Pediatrics, 19, 504.

Perkins, J. F., Adams, W. E., Flores, A., Harper, P. V. and Landahl, H. D. (1958). Arterial oxygen saturation vs. alveolar oxygen tension in anatomical venous-arterial shunting. J.appl. Physiol., 12,71 .

Rosenthal, T. B. (1948). The effect of temperature on the $\mathrm{pH}$ of blood and plasma in vitro. J. biol. Chem., 173, 25.

Roughton, F. J. W., Darling, R. C. and Root, W. S. (1944). Factors affecting the determination of oxygen capacity, content and pressure in human arterial blood. Amer. J. Physiol., 142, 708.

Rudolph, A. M., Drorbaugh, J. E., Auld, P. A. M., Rudolph, A. J., Nadas, A. S., Smith, C. A. and Hubbell, J. P. (1961). Studies on the circulation in the neonatal period: the circulation in the respiratory distress syndrome. Pediatrics, $27,551$.

Sendroy, J., Dillon, R. T. and Van Slyke, D. D. (1934). The solubility and physical state of uncombined oxygen in blood. J. biol. Chem., 105, 597.

Severinghaus, J. W. (1958). Oxyhemoglobin dissociation curve correction for temperature and $\mathrm{pH}$ variation in human blood. J. appl. Physiol., 12, 485.

Shepard, R. H. (1958). Effect of pulmonary diffusing capacity on exercise tolerance. ibid., 12, 487.

Silverman, W. A. (1961). The effect of the atmospheric environment on the premature infant. J. Pediat., 58, 581.

and Andersen, D. H. (1956). A controlled clinical trial of effects of water mist on obstructive respiratory signs, death rate and necropsy findings among premature infants. Pediatrics, $17,1$.

and Blanc, W. A. (1957). The effect of humidity on survival of newly born premature infants. ibid., $20,477$.

Smith, F. J. C., Bennett, G. A., Heim, J. W., Thomson, R. M. and Drinker, C. K. (1932). Morphological changes in the lungs of rats living under compressed air conditions. J. exp. Med., 56, 79 .

Stahlman, M. (1961). In discussion of Nelson et al. (1961).

, Merrill, R., Lequire, V. S. and James, L. S. (1961). Functional patency of the via sinistra after birth. Amer. J. Dis. Child., 102,561 .

Strang, L. B. and MacLeish, M. H. (1961). Ventilatory failure and right-to-left shunt in newborn infants with respiratory distress. Pediatrics, 28, 17.

Tran Dinh De and Anderson, G. W. (1954). The experimental production of pulmonary hyaline-like membranes with atelectasis. Amer. J. Obstet. Gynec., 68, 1557.

Usher, R. H. (1961). The metabolic changes in respiratory distress syndrome of prematurity seen as a failure of somatic compensations for asphyxia. In Ciba Foundation Symposium on Somatic Stability in the Newly born, ed. G. E. W. Wolstenholme and M. O'Connor, p. 92. Churchill, London. 